\section{Letter from the Founding Facilitator} Richard J. Barohn, MD

Welcome to Vol $2 /$ Issue 3 of the RRNMF Neuromuscular Journal. This issue once again contains a plethora of new neuromuscular information. In addition, we once again are publishing some wonderful pieces from the arts and sciences that are not neuromuscular at all, but very much worth reading. The first section begins with "What's on Your Mind?," and I have asked Dr. Joshua Freeman to again allow us to publish one of his insightful articles he posts on his blog sites (he has two of them) about the dangers surrounding medically related direct-to-consumer advertising on TV. I have an article I first wrote for one of my Executive Vice Chancellor messages at the University of Missouri in honor of Black History Month; I highlighted the amazing career of Dr. Patricia Bath, a pioneer in Ophthalmology. Dr. Raghav Govindarajan has another great article about a journey he and a patient took together through their physician-patient relationship he titled "The Last Ride”. In an attempt to expose my neuromuscular colleagues to some old-fashioned psychoanalytic thinking, I have asked my good friend and psychoanalyst Walter Ricci MD to allow us to publish two of his short pieces on the role of "shame" in our lives. This year is also the 25th anniversary of the Kansas City Psychoanalytic Institute, which Dr. Ricci founded with several colleagues. We are publishing a short piece Dr. Ricci wrote for that organization's newsletter. Yes, my neuromuscular friends, despite rumors of its demise, psychoanalysis is alive and thriving in the United States.

Back to neuromuscular disease and New Stuff! Dr. Mehta and the University of Missouri group discuss their experience using botulinum toxin for cramps in patients with neuropathy. Dr. Pocock and the group from Seattle have an intriguing article on the possible relationship between amyotrophic lateral sclerosis and multiple sclerosis. Dr. Menon, Dr. Brill and colleagues from the University of Toronto and CSL Behring report a sub-analysis from the pivotal polyneuropathy and treatment with Hizentra (PATH) study by investigating the distal compound muscle action potential and temporal dispersion as variables and secondary outcome measures. Dr. Rashid and colleagues from KabaFusion report their large home infusion experience of over 11,000 infusions and how infusion rate influences side effects of intravenous immunoglobulin (IVIG) infusions.

In the Clinic Stuff category, Dr. Menon and Brill (and Dr. Alnajjar) from the University of Toronto have another article in this issue describing a patient with a distal acquired demyelinating symmetric (DADS) neuropathy phenotype who ended up being diagnosed with primary amyloidosis and they ask the question: are the two related? Drs. Bhagavan, Beladakere Ramaswamy and Govindarajan from the University of Missouri report elevated liver transaminase enzyme elevation in a patient with Guillain Barre Syndrome
(GBS). The neurology group in Philadelphia led by Dr. Prabhu has an interesting case first authored by student Ryan Fogg of a myasthenia gravis (MG) patient with a thymoma and the complication of pericarditis. Drs Rim and Li from the Cleveland Clinic describe the association of GNE myopathy and thrombocytopenia, which interestingly has previously been reported, and they review the literature. Dr. Alcantara and her team in Toronto, led by Dr. Hans Katzberg, describe a complicated case presenting with dyspnea and sleep apnea who was ultimately diagnosed with MG and MuSK antibodies and who responded to Rituximab.

In the Proposed Stuff category, we are publishing two grants: one that was not funded and one that was funded. The Kansas/Missouri group is publishing an unsuccessful PCORI grant we submitted several years ago. This was a proposal to do a comparative effectiveness study in CIDP of intravenous immunoglobulin (IVIg) versus subcutaneous immunoglobulin (SCIg). We are attaching the critiques from the reviewers, the ultimate (and painful) peer review. The purpose of publishing unfunded grant attempts and critiques is several-fold. If others are considering studying this clinical question, they do not have to start from ground zero and can see where others have tread and failed. If that happens, hopefully another group will take what we proposed and the critiques and come up with a better and findable approach. Another is of course that a great deal of time, effort, and teamwork goes into preparing these complicated multi-center trials. It seems reasonable to expect that at the least the team can potentially publish their work, along with the criticisms. Why no one has thought of publishing failed and accepted grants with critiques before is beyond me, but I am unaware of any other journal that does this.

In addition, we are publishing the successfully funded FDA Orphan Products Division ROl, Phase II study of Arimoclomol in IBM. This was funded in 2015. Dr Mazen Dimachkie was, and is, the principal investigator. In Volume 2, Issue 2 of the RRNMF Neuromuscular Journal, he and his team published the story of the evolution of the arimoclomol in IBM project. In this issue we publish the actual grant that was funded with the critiques from the study section. Again, the ultimate peer review. The project that the grant finished is now winding down and results will be published soon.

Finally, in the section we are calling "Art and other stuff" we have two poems and a screenplay. On the arts end of the spectrum, I invited my good colleagues Drs. Vernon (Bud) and Elizabeth (Betsy) Rowe to publish some of their poetry in this journal. Both Dr. Rowes are impressive neuroscientists, and they also are equally impressive and well published poets. Also in the arts category, I have asked my friend Walter (also a "Bud") Anderson to allow us to publish a new screenplay he has written, "27 Crossroads." Bud and I were in the Medical Corp of the U.S. Air Force 
What's On Your Mind?

together, stationed at RAF Alconbury in the United Kingdom in the early 1980s. We were roommates, living in "The Longhouse" in a village called Over, on the Ouse River near Cambridge. Those were wonderful times and Bud and I have stayed fast friends over the decades. He went on to have a very successful career as a sound engineer on the sets of movies and television productions and lives in Manhattan Beach, California with his family. He is an excellent writer as well and has a couple of plays written. I thought this would be a good place for one of them to be published so my other medical friends can learn more about the talents of my good friend on the West Coast. This play takes place in England and you will be surprised who the characters turn out to be, and the bluesman they may have been influenced by.

The wonderful art on the cover is a diptych by San Antonio artist Vincent Valdez from the Barohn art collection. The blue painting is called "Yo Soy-ee Blaxican" and the red painting is called "Ah Yes, That Notorious Place Everyone Speaks Of".

I am looking forward to the next issue of the RRNMF Neuromuscular Journal as in that issue we will publish the abstracts from the upcoming Muscle Study Group meeting on Oct 1 through 3. This year again the annual MSG meeting will be virtual due to the covid pandemic. We are also hoping that many of the presenters of abstracts will have submitted full length articles for that issue as well. This will be a new feature for the journal- to publish full length articles that will be presented at the meeting in addition to all of the abstracts. We will also, for the first time, provide our industry partners who support the MSG meeting a space for information about their company or their products. We plan to publish that issue in mid-September. To register for the MSG meeting go to https://musclestudygroup.org/events/2021muscle-study-group-annual-scientific-meeting/

Rick 